Original article

https://www.journal-imab-bg.org

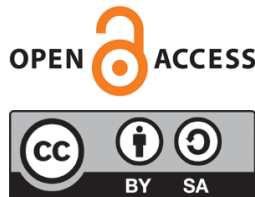

\title{
ANTIBACTERIAL AND ANTIFUNGAL ACTIVITY OF ANTIPERSPIRANT COSMETIC PRODUCTS
}

\author{
Neli Ermenlieva ${ }^{1}$, Emilia Georgieva ${ }^{2}$, Minko Milev ${ }^{3}$ \\ 1) Department of Microbiology and Virology, Faculty of Medicine, Medical \\ University - Varna, Bulgaria \\ 2) TRS "Medical laboratory assistant", Medical College, Medical University- \\ Varna, Bulgaria \\ 3) TRS "Dental technician", Medical College, Medical University-Varna, \\ Bulgaria.
}

\section{ABSTRACT}

In most deodorant products, antibacterial agents such as aluminum salts, alcohol and aromatic odor-masking agents, are used.

Aim: The aim of the study is to evaluate the antimicrobial activity of antiperspirant cosmetic products consist of Aluminum Chlorohydrate and Alcohol to normal skin microflora and conditionally pathogenic bacteria, which can cause skin infections.

Material and Methods: Antimicrobial activity was tested with strains $S$. epidermidis, $S$. aureus, C. albicans, $S$. pneumoniae and E. coli. The left half of media with microbial seeds was sprayed with antiperspirant cosmetic product at a distance of $15 \mathrm{~cm}$ for 3-4 seconds (Figures 1-5), and the other half was covered with wrapping paper.

Results and Conclusion: Cosmetic products containing Aluminum Chlorohydrate demonstrate almost total inhibition of microbial growth. Complete suppression of the normal microbiota of the skin can lead to skin vulnerability in the armpit area. Antiperspirant cosmetic product containing Alcohol has antibacterial no inhibiting effects against $S$. epidermidis and demonstrated efficacy against $S$. pneumoniae and C. albicans.

Keywords: antibacterial activity, antifungal activity, cosmtic products, antiperspirants

\section{INTRODUCTION}

The skin is colonized by a diverse milieu of microorganisms, most of which are harmless and even beneficial to their host. The human skin microbial habitat is personspecific [1, 2], usually predominate Gram-positive bacteria (staphylococci, micrococci, diphtheroids) [3, 4], commensal fungi [5] and others. In some cases, the normal flora can be associated with different types of infections, presented in Table 1.

Table 1. Normal skin flora and some infection disease caused by resident skin bacteria.

\begin{tabular}{|l|l|}
\hline $\begin{array}{l}\text { Staphylococcus } \\
\text { epidermidis }\end{array}$ & $\begin{array}{l}\text { Sepsis, endocarditis, } \\
\text { wound infection }\end{array}$ \\
\hline Staphylococcus & Impetigo \\
\hline aureus & Erythrasma \\
\hline $\begin{array}{l}\text { Corynebacterium } \\
\text { minitissimum }\end{array}$ & Acne vulgaris \\
\hline Propionibacterium & Intertrigo \\
\hline
\end{tabular}

Sweat glands secretion is by itself odorless, and armpit malodor is caused by the microbial biotransformation of the odorless secretion into volatile odorous molecules $[6,7]$. Nowadays, in most deodorant products, antibacterial agents such as triclosan, aluminum salts, alcohol and aromatic odor-masking agents, are used.

\section{AIM}

The aim of the study is to evaluate the antibacterial and antifungal activity of three antiperspirant cosmetic products consist of Aluminum Chlorohydrate and Alcohol to normal skin microflora and conditionally pathogenic bacteria, which can cause skin infections.

\section{MATERIALS AND METHODS}

The study was conducted in Medical Collage Varna, Bulgaria. We use three market products antiperspirant deodorant sprays with ingredients presented in Table 2 . 
Table 2. Main ingredients with antimicrobial efficacy in antiperspirant cosmetic products using in the study.

\begin{tabular}{|l|l|l|}
\hline Market Product & Ingredients & Action \\
\hline \multirow{2}{*}{ Deo Spray 1 } & Alcohol & inhibit bacterial and fungal growth \\
\cline { 2 - 3 } & Phenoxyethanol & antiseptic, solvent and preservative \\
\hline \multirow{2}{*}{$\begin{array}{l}\text { Deo Spray 2 } \\
\text { Deo Spray 3 }\end{array}$} & Aluminum Chlorohydrate & $\begin{array}{l}\text { antiperspirant (reduces the secretion of sweat) and } \\
\text { deodorant (reduces bad odor by inhibiting bacterial growth) }\end{array}$ \\
\cline { 2 - 3 } & Benzyl alcohol & $\begin{array}{l}\text { solvent and preservative with antibacterial and antifungal } \\
\text { properties }\end{array}$ \\
\cline { 2 - 3 } & Geraniol & \begin{tabular}{l} 
improve the aroma and showed a large bactericidal activity \\
\hline
\end{tabular}
\end{tabular}

Antimicrobial activity of antiperspirant cosmetic products was tested with strains Staphylococcus epidermidis, Staphylococcus aureus, Candida albicans, Streptococcus pneumoniae and Escherichia coli.

The used method includes a dense seed with standardized bacterial and fungal culture on an appropriate nutrient medium. The media were left at room temperature for 30 minutes. The half of each agar was sprayed with the antiperspirant cosmetic product at a distance of $15 \mathrm{~cm}$ for $3-$ 4 seconds. The other half was covered with wrapping paper. Each sample was made in triplicate. The results were reported after 24 hours of aerobic incubation at $37^{\circ} \mathrm{C}$.

\section{RESULTS AND DISCUSSION}

Cosmetic products containing Aluminum Chlorohydrate demonstrate almost total inhibition of microbial growth (one sample with growth - strain Escherichia coli). Antiperspirant cosmetic product containing Alcohol demonstrates antimicrobial activity against $S$. pneumoniae and C. albicans, but not against $S$. epidermidis, S. aureus, E. coli. The results are shown in Table 3 and Figure 1 - Figure 5 .

Table 3. Antibacterial and antifungal activity of three antiperspirant cosmetic products consist of Aluminum Chlorohydrate and Alcohol to normal skin microflora and conditionally pathogenic bacteria, which can cause skin infections.

\begin{tabular}{|l|c|c|c|c|c|}
\hline Product (Active Ingredient) & S. epidermidis & S. aureus & S. pneumoniae & E. coli & C. albicans \\
\hline $\begin{array}{l}\text { Deo Spray 1 } \\
\text { (Alcohol) }\end{array}$ & + & + & - & + & - \\
\hline $\begin{array}{l}\text { Deo Spray 2 } \\
\text { (Aluminum Chlorohydrate) }\end{array}$ & - & - & - & $-/+$ & - \\
\hline $\begin{array}{l}\text { Deo Spray 3 } \\
\text { (Aluminum Chlorohydrate) }\end{array}$ & - & - & - & - & - \\
\hline
\end{tabular}

$+\quad$ Visible microbial growth

- No microbial growth

Fig. 1 - Fig. 5. Antimicrobial activity of antiperspirant cosmetic products:

The left half was sprayed with the antiperspirant cosmetic product at a distance of $15 \mathrm{~cm}$ for 3-4 seconds

(1 - Deo Spray 1 (Alcohol); 2 - Deo Spray 2 (Aluminum Chlorohydrate); 3 - Deo Spray 3 (Aluminum Chlorohydrate)). The right half was covered with wrapping paper. Each sample was made in triplicate.

Fig. 1. Staphylococcus epidermidis on Blood agar.

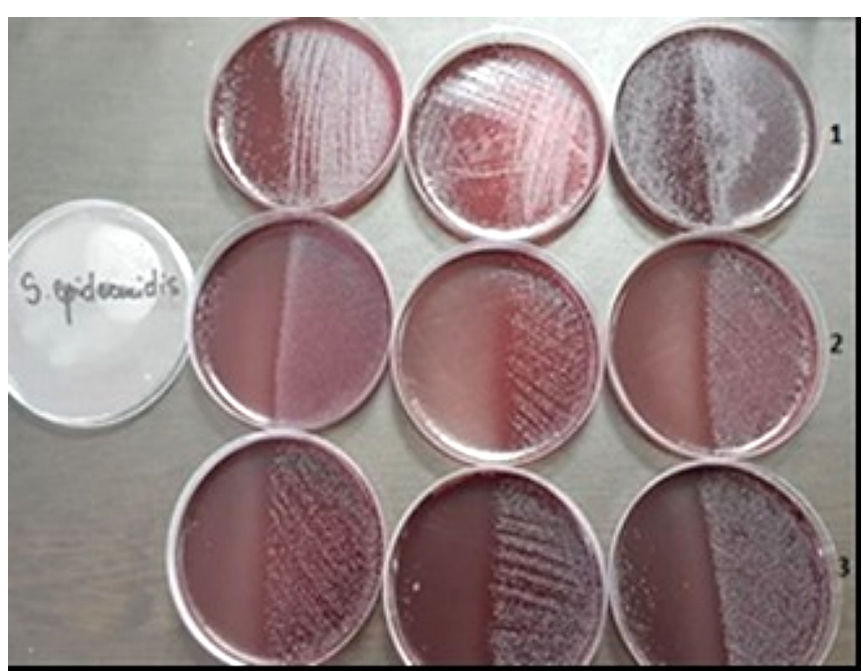


Fig. 2. Staphylococcus aureus on Blood agar.

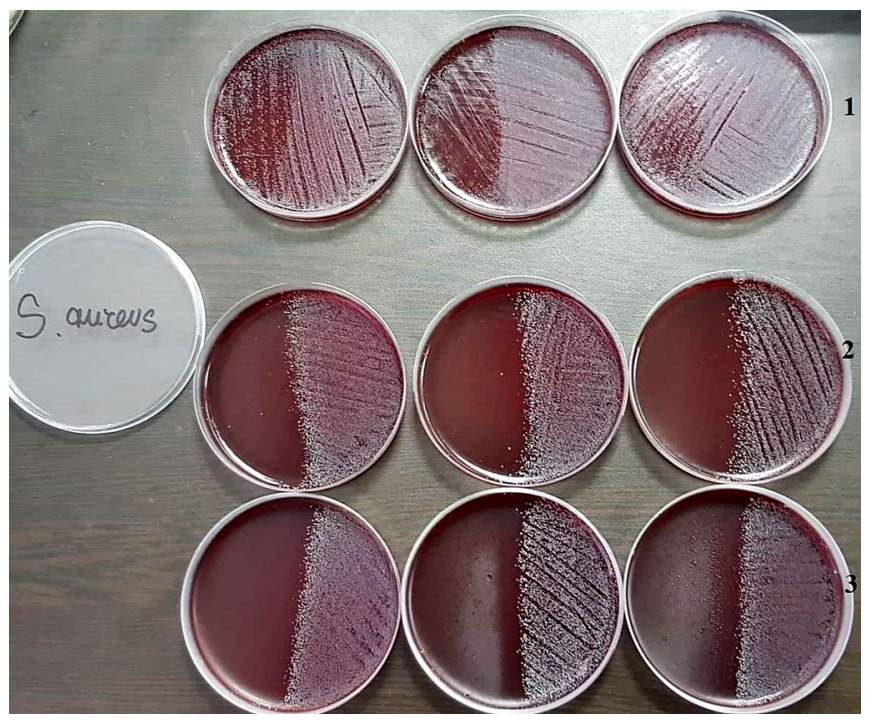

Fig. 3. Streptococcus pneumoniae on Blood agar.



Fig. 4. Escherichia coli on MacConkey agar.

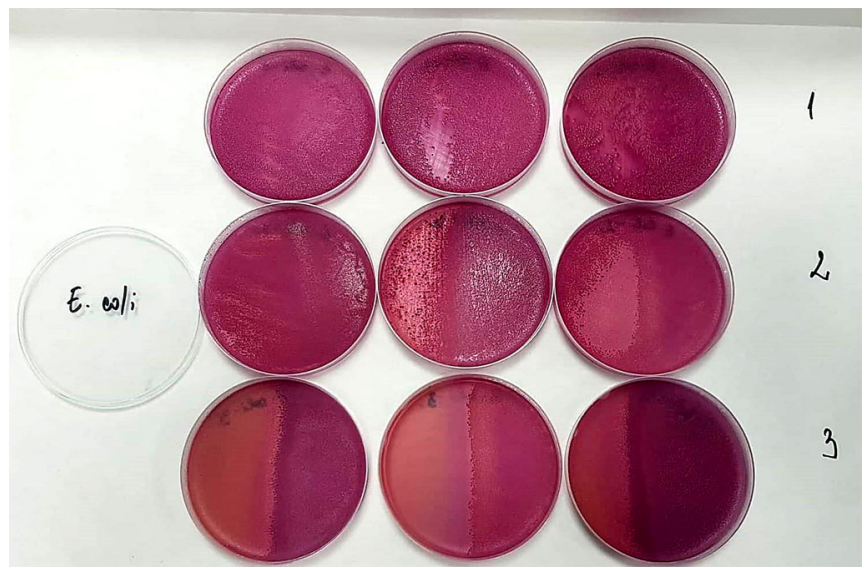

Fig. 5. Candida albicans on Sabouraud agar.



\section{CONCLUSION}

Cosmetic products containing Aluminum Chlorohydrate with high cosmetic efficiency, however, lead to complete suppression of the normal microbiota of the skin such as S. epidermidis. This systemic effect can lead to skin vulnerability in the armpit area and subsequent pathological effects.

Antiperspirant cosmetic product containing Alcohol has no inhibiting effects against $S$. epidermidis. If these Alcohol-deodorant sprays lead to a satisfactory cosmetic effect (reducing the sweat and odor), we recommend their use as a more supportive product to the resident skin bacteria, part of the human natural resistance. 
REFERENCES: 1. Bouslimani A, da Silva R,
Kosciolek T, Janssen S, Callewaert C, Amir A, et al. The impact of skin care products on skin chemistry and microbiome dynamics. BMC Biol. 2019 Jun 12;17:47. [PubMed] [Crossref]

2. Oh J, Byrd AL, Deming C, Conlan S, Kong HH, Segre JA. Biogeography and individuality shape function in the human skin metagenome. Nature. 2014 Oct 2;514(7520):59-64. [PubMeb]

3. Benohanian A. Antiperspirants and deodorants. Clin Dermatol. 2001
Jul-Aug;19(4):398-405. [PubMed] [Crossref]

4. Shahtalebi MA, Ghanadian M, Farzan A, Shiri N, Shokri D, Fatemi SA. Deodorant effects of a sage extract stick: Antibacterial activity and sensory evaluation of axillary deodorancy. J Res Med Sci. 2013 Oct; 18(10):833-9. [PubMed]

5. Ibryamova $\mathrm{S}$, Hasanov $\mathrm{H}$, Ignatova-Ivanova T. Antifungal activity of a phosphorylated 3-(alfahydroxyalkyl) allenes ethanol extracts. J of IMAB. $2020 \mathrm{Jul-Sep;}$
26(3):3328-3332. [Crossref]

6. Lam TH, Verzotto D, Brahma P, Ng AHQ, Hu P, Schnell D, et.al. Understanding the microbial basis of body odor in pre-pubescent children and teenagers. Microbiome. 2018 Nov 29;6(1):213. [PubMed] [Crossref]

7. Urban J, Fergus DJ, Savage AM, Ehlers M, Menninger HL, Dunn RR, et al. The effect of habitual and experimental antiperspirant and deodorant product use on the armpit microbiome. Pee rJ. 2016 Feb 2;4: e1605. [PubMed] [Crossref]

Please cite this article as: Ermenlieva N, Georgieva E, Milev M. Antibacterial and antifungal activity of antiperspirant cosmetic products. J of IMAB. 2020 Oct-Dec;26(4):3374-3377. DOI: https://doi.org/10.5272/jimab.2020264.3374

Received: 04/11/2019; Published online: 07/10/2020

Address for correspondence:

Neli Mitkova Ermenlieva

Department of Microbiology and Virology, Faculty of Medicine, Medical University Varna,

3. Bregalniza Str.. 9002 Varna, Bulgaria.

E-mail: n.ermenlieva@abv.bg 